\title{
openheart Minimally invasive mitral valve surgery: a systematic safety analysis
}

\author{
Kinsing Ko (D) , ${ }^{1}$ Thom L de Kroon, ${ }^{1}$ Marco C Post, ${ }^{2,3}$ Johannes C Kelder, ${ }^{2}$ \\ Karen F Schut, ${ }^{4}$ Nabil Saouti, ${ }^{1}$ Bart $P$ van Putte ${ }^{1,4}$
}

\begin{abstract}
- Additional material is published online only. To view, please visit the journal online (http://dx.doi.org/10.1136/ openhrt-2020-001393).
\end{abstract}

To cite: Ko K, de Kroon TL, Post MC, et al. Minimally invasive mitral valve surgery: a systematic safety analysis. Open Heart 2020;7:e001393.

doi:10.1136/

openhrt-2020-001393

KK and TLdK contributed equally.

NS and BPvP contributed equally.

Received 16 July 2020 Revised 1 September 2020 Accepted 4 September 2020

Check for updates

(C) Author(s) (or their employer(s)) 2020. Re-use permitted under CC BY-NC. No commercial re-use. See rights and permissions. Published by BMJ.

${ }^{1}$ Cardiothoracic Surgery, St. Antonius Hospital, Nieuwegein, The Netherlands

${ }^{2}$ Cardiology, St. Antonius Hospital, Nieuwegein, The Netherlands

${ }^{3}$ Cardiology, UMC Utrecht, Utrecht, The Netherlands ${ }^{4}$ Cardiothoracic Surgery, Amsterdam UMC, Amsterdam, The Netherlands

Correspondence to Mr Kinsing Ko; kinsingko@ gmail.com

\section{ABSTRACT}

Objective Minimally invasive surgery is increasingly adopted as an alternative to conventional sternotomy for mitral valve pathology in many centres worldwide. A systematic safety analysis based on a comprehensive list of pre-specified 30-day complications defined by the Mitral Valve Academic Consortium (MVARC) criteria is lacking. The aim of the current study was to systematically analyse the safety of minimally invasive mitral valve surgery in our centre based on the MVARC definitions. Methods All consecutive patients undergoing minimally invasive mitral valve surgery through right minithoracotomy in our institution within 10 years were studied retrospectively. The primary outcome was a composite of 30-day major complications based on MVARC definitions. Results 745 patients underwent minimally invasive mitral valve surgery (507 repair, 238 replacement), with a mean age of $62.9 \pm 12.3$ years. The repair was successful in $95.8 \%$. Overall 30 -day mortality was $1.2 \%$ and stroke rate $0.3 \%$. Freedom from any 30 -day major complications was $87.2 \%$, and independent predictors were left ventricular ejection fraction $<50 \%$ (OR 1.78; $95 \% \mathrm{Cl} 1.02$ to 3.02 ) and estimated glomerular filtration rate $<60 \mathrm{~mL} / \mathrm{min} / 1.73 \mathrm{~m}^{2}$ (OR 1.98; 95\% Cl 1.17 to 3.26).

Conclusions Minimally invasive mitral valve surgery is a safe technique and is associated with low 30-day mortality and stroke rate.

\section{INTRODUCTION}

The feasibility of minimally invasive mitral valve surgery (MIMVS) has been proven extensively and numerous high-volume centres have adopted this technique as a standard approach. ${ }^{1-4}$ There is currently much literature available, but without evidence of superiority or inferiority of MIMVS compared with sternotomy. Multiple studies reported similar or favourable perioperative outcomes of MIMVS compared with standard sternotomy, but only two of them are randomised controlled trials, ${ }^{56}$ most of them are observational, ${ }^{1-4}$ and some of them are propensitymatched cohorts. ${ }^{7}$ There is currently one large trial running in the UK (UK Mini Mitral Trial), for which we are still awaiting the results. ${ }^{8}$ Nonetheless, increasingly centres worldwide report promising results, ${ }^{910}$ which

\section{Key questions}

What is already known about this subject?

- The safety of minimally invasive mitral valve surgery (MIMVS) is reported in many retrospective studies with favourable and well-defined 30-day stroke and mortality rates. However, composite outcomes such as major complications, major adverse cardiac events and major adverse cardiac and cerebrovascular events are poorly defined and reported at a wide range of $6.5 \%-33.0 \%$. A systematic safety analysis of MIMVS based on a comprehensive list of pre-specified 30-days major complications rate defined by the Mitral Valve Academic Consortium (MVARC) endpoint and safety criteria is lacking.

What does this study add?

- To the best of our knowledge, this is the first study reporting outcome of MIMVS according to MVARC definitions. The mitral valve repair was successful in $95.8 \%$, with an overall 30 -day mortality of $1.2 \%$ and stroke rate of $0.3 \%$. Freedom from any 30 -day major complications was $87.2 \%$, independent predictors were a decreased left ventricular ejection fraction and renal function.

How might this impact on clinical practice?

- MIMVS is a safe technique with favourable 30-day outcome such as a low 30 -day mortality and stroke rate.

suggests that MIMVS is reproducible in a safe way with results equal to sternotomy. Most clearly reported benefits of MIMVS over sternotomy are faster return to daily activities and higher patient's satisfaction of cosmetics. ${ }^{11}$ To achieve these benefits related to the surgical access site, MIMVS should never compromise the quality of the procedure and safety endpoints of the standard surgical treatment. However, a systematic safety analysis based on a comprehensive list of pre-specified 30-day major complications rate is still lacking. In previously mentioned studies, there is no consistency in definitions for adverse events, serious adverse events, major adverse cardiac events and major adverse cardiac and cerebrovascular events (MACCEs), which is a known issue in surgical research. ${ }^{12}$ The Mitral 


\begin{tabular}{|c|c|c|c|}
\hline & & \multicolumn{2}{|c|}{$\mathrm{N}=745$} \\
\hline \multicolumn{2}{|l|}{ Age mean $\pm S D$, years } & \multicolumn{2}{|c|}{$62.9 \pm 12.3$} \\
\hline \multicolumn{2}{|l|}{ Female } & 327 & $43.9 \%$ \\
\hline \multicolumn{2}{|c|}{ Body mass index mean $\pm \mathrm{SD}, \mathrm{kg} / \mathrm{m}^{2}$} & \multicolumn{2}{|c|}{$25.4 \pm 3.9$} \\
\hline \multicolumn{2}{|l|}{ Euroscore 1 mean $\pm S D$} & \multicolumn{2}{|c|}{$4.5 \pm 2.2$} \\
\hline \multicolumn{2}{|l|}{ Euroscore 2 mean \pm SD } & \multicolumn{2}{|c|}{$1.4 \pm 1.2$} \\
\hline \multicolumn{2}{|l|}{ Diabetes mellitus } & 39 & $5.2 \%$ \\
\hline \multicolumn{2}{|l|}{ Atrial fibrillation } & 272 & $36.5 \%$ \\
\hline \multicolumn{2}{|c|}{ Peripheral vascular disease } & 6 & $0.8 \%$ \\
\hline \multicolumn{2}{|l|}{$\mathrm{eGFR}<60 \mathrm{~mL} / \mathrm{min} / 1.73 \mathrm{~m}^{2}$} & 119 & $16.0 \%$ \\
\hline \multicolumn{2}{|l|}{ Stroke } & 37 & $5.0 \%$ \\
\hline \multicolumn{2}{|l|}{ Transient ischaemic attack } & 31 & $4.2 \%$ \\
\hline \multirow[t]{4}{*}{ COPD } & GOLD 1 & 21 & $2.8 \%$ \\
\hline & GOLD 2 & 24 & $3.2 \%$ \\
\hline & GOLD 3 & 7 & $0.9 \%$ \\
\hline & GOLD 4 & 3 & $0.4 \%$ \\
\hline \multirow[t]{2}{*}{ Endocarditis } & Active & 2 & $0.3 \%$ \\
\hline & Healed & 22 & $3.0 \%$ \\
\hline \multicolumn{2}{|c|}{ Good left ventricular function } & 640 & $86.0 \%$ \\
\hline \multicolumn{2}{|c|}{ Good right ventricular function } & 731 & $98.2 \%$ \\
\hline \multirow[t]{3}{*}{ Pulmonary hypertension } & Yes & 264 & $37.4 \%$ \\
\hline & No & 441 & $62.6 \%$ \\
\hline & Missing & 40 & \\
\hline
\end{tabular}

COPD, chronic obstructive pulmonary disease; eGFR, estimated glomerular filtration rate.

Valve Academic Consortium (MVARC) provided clear endpoint and safety definitions for treatment of mitral regurgitation, with emphasis on transcatheter therapies. ${ }^{13}$ Nonetheless, these definitions should be used for surgical treatment for mitral regurgitation as well to provide uniform results for comparison purposes. The aim of this study is to assess the safety of MIMVS by reporting all the complications during a 30-day follow-up in a systematic fashion with an emphasis on major complications based on MVARC definitions.

\section{MATERIALS AND METHODS}

\section{Patient and public involvement}

Patients and/or the public were not involved in the setting of this research due to its retrospective design, nor were they burdened with additional investigations, treatment or questionnaires.

\section{Preoperative decision-making process}

All patients referred for mitral valve surgery were discussed in the heart team. Consecutive patients with an indication for mitral valve surgery with or without concomitant tricuspid valve and/or maze surgery and/ or closure of atrial septal defect were scheduled for MIMVS. Exclusion criteria for MIMVS were previous right thoracotomy, concomitant procedures other than aforementioned (eg, bypass surgery, aortic valve replacement) or severe peripheral vascular disease. Patients with previous cardiac surgery were operated on through MIMVS in our institution, but were excluded for current analysis.

\section{Repair decision-making process}

Assessment to repair the mitral valve was based on preoperative echocardiographic mechanism of mitral valve disease, (expected) tissue quality and clinical characteristics (eg, age). Annular dilatation and functional mitral regurgitation were repaired with ring annuloplasty. Ischaemic mitral regurgitation was repaired with an undersized ring. Prolapse of leaflets was repaired with triangular/quadrangular resection and sliding plasty of the annulus in the earliest patients. Starting from the end of 2009, the vast majority of the isolated prolapsing leaflets was repaired with neochordae combined with annuloplasty ring. Barlow disease was standardly repaired with a large annuloplasty ring combined with edge-toedge stitch of scallops A2/P2. ${ }^{14}$ After every repair, a transesophageal echocardiography was made intraoperatively to assess valve function. In case of residual MR more than grade 1, and/or mean pressure gradient $>5 \mathrm{~mm} \mathrm{Hg}$ and/or systolic anterior motion, a second pump run was considered in order to restore.

\section{Data collection and definitions}

Medical charts and records were collected for all patients, including demographics, operation notes and postoperative data between 2005 and 2015 (consecutive series). If a patient was transferred to another hospital, we contacted the referral hospital to retrieve postoperative data to complete the 30-day follow-up. For mortality, the Dutch civil register was consulted. All data regarding 30-day complications were collected according a prespecified list of complications based on MVARC criteria. ${ }^{13}$ Composite of 30-day major complications was based on MVARC criteria and consisted of 30-day mortality, conversion to sternotomy, myocardial infarction, stroke, renal injury AKIN class II-III, any surgical reintervention (eg, bleeding, empyema or failed repair), prolonged ventilation $>48$ hours, low cardiac output syndrome (LCOS) $>48$ hours or necessity for mechanical support. ${ }^{13}$ Low cardiac output syndrome LCOS was defined as the necessity for inotropes $>30 \mathrm{~min}$ after correcting for fluid state, ${ }^{15}$ which we separated in three categories: requiring $<48$ hours of support, requiring $>48$ hours of support and requiring mechanical support.

\section{Endpoints}

Primary endpoint was freedom from 30-day major complications, and secondary endpoint was freedom from any 30-day complications.

\section{Surgical technique}

Our surgical technique is based on the Leipzig approach. ${ }^{1}$ Cardiopulmonary bypass was instituted by 
Table 2 Mitral valve disease aetiology and indication for surgery $(\mathrm{N}=745)$

\begin{tabular}{|lll}
\hline & $\mathbf{n}$ & \% \\
\hline Regurgitation & 695 & 93.3 \\
\hline Carpentier type 1 & 120 & 17.3 \\
\hline Carpentier type 2 & 535 & 77.0 \\
\hline Carpentier type 3a & 25 & 3.6 \\
\hline Carpentier type 3b & 15 & 2.2 \\
\hline Aetiology for regurgitation & & \\
\hline Degenerative & 534 & 76.8 \\
\hline Annular dilatation & 109 & 15.7 \\
\hline Ischaemic/dilated & 16 & 2.3 \\
\hline cardiomyopathy & & \\
\hline Endocarditis & 14 & 2.0 \\
\hline Rheumatic & 16 & 2.3 \\
\hline Post-radiation & 6 & 0.9 \\
\hline Stenosis & 30 & 4.0 \\
\hline Rheumatic & 27 & 90.0 \\
\hline Degenerative & 3 & 10.0 \\
\hline Combined & 20 & 2.7 \\
\hline Rheumatic & 16 & 80.0 \\
\hline Degenerative & 4 & 20.0 \\
\hline & & \\
\hline & & \\
\hline
\end{tabular}

groin cannulation. In case of concomitant tricuspid valve surgery or atrial septal defect, a second venous cannula was inserted through the right jugular vein until 2012 to establish total bypass. After this period, a bicaval cannula of LivaNova PLC (London, UK) was used for all operations, and in case of tricuspid valve surgery and/or atrial septum closure with snares around the superior and inferior vena cava. Surgical access was obtained by a right anterolateral mini-thoracotomy of approximately $4-5 \mathrm{~cm}$ through the fourth intercostal space. Aortic occlusion was performed with a Chitwood clamp. In 2014 and 2015, the Edwards IntraClude Intra-Aortic Balloon Occlusion Device (Irvine, California, USA) was used in 10 random patients. Selection of these patients was independent of patient factors, but rather on logistics only. Concomitant left maze surgery was performed in patients with atrial fibrillation by creating a left atrial box lesion set by Atricure cryICE (Mason, Ohio, USA). In most patients, the left atrial appendage was left untreated.

\section{Statistical analysis}

Univariate and multivariate analysis for predictors for complications were performed in SPSS Statistics for Windows, V.24.0 (IBM. Released 2016). Univariate analysis was done and variables with a $\mathrm{p}$ value of less than 0.1 or clinically relevant predictors were selected for inclusion in a multivariate logistic regression model. First, all selected covariates were entered in a multivariate logistic regression model, followed by forward conditional selection to explore the statistically strongest predictors.
Second, all selected covariates were entered again into a second logistic regression model, followed by manual backward elimination based on statistical significance and clinical relevance. Predictors with a $\mathrm{p}$ value of less than 0.05 in our final model after manual backward elimination were considered as independent predictors for complications. The maximum number of covariates for our prediction model was set at $10 \%$ of the number of the outcome event.

\section{RESULTS \\ Baseline characteristics}

Baseline characteristics are shown in table 1. All patients but two were operated on electively after routine check-up. The two emergency patients were in cardiac shock due to acute severe mitral regurgitation, in one patient caused by papillary muscle rupture after a myocardial infarction and needed extracorporeal membrane oxygenation (ECMO) for several days. Both patients survived.

\section{Mitral valve repair, intraoperative characteristics and hospital/ICU admission}

Table 2 shows aetiology of mitral valve disease and indications for surgery. The repair techniques used are described in table 3 and figure 1 shows a flowchart of repairability assessment.

An edge-to-edge repair was only standardly performed in patients with Barlow's disease ${ }^{14}$ since it is our standard approach, except in eight patients. Of these patients, two were due to systolic anterior motion of the mitral valve and received an edge-to-edge repair during a second pump run, in two patients as a bail-out and in four patients to prevent systolic anterior motion of the mitral valve. Success rate of repair was 95.8\% (502/524). Of the repairable valves, $9.3 \%(54 / 578)$ were intentionally replaced since a repair was expected to have limited durability and/or that the benefit of replacement by bioprosthetic valve outweighs the risk of redo for unsuccessful repair, mainly in octogenarians (mean age $79 \pm 4$ years). ${ }^{16}$ Other reasons for replacement in repairable valves are shown in figure 1. All patients at discharge had no more than trace or mild regurgitation. Median ventilation time was $470 \mathrm{~min}$ (IQR 355-630). Median intensive care admission was 1 day (IQR 1-2). Median hospital stay was 7 days (IQR 6-10). Median hospital stay for patients in our hospital was 7 days (IQR 6-9), and median hospital stay for patients from referral hospital was 9 days (IQR 7-13).

\section{0-Day mortality}

The overall 30-day mortality was $1.2 \%$ (9/745), $0.4 \%$ $(2 / 507)$ for mitral valve repair and $2.9 \%$ (7/238) for mitral valve replacement. The overall 30-day cardiacrelated mortality was $0.9 \%(7 / 745)$ of which one patient had cardiogenic shock due to cardiac amyloidosis (confirmed in postmortem pathological investigation), one patient had intraoperative aortic dissection, one patient had severe and uncontrollable bleeding from a 


\begin{tabular}{|c|c|c|}
\hline & $\mathbf{n}$ & $\%$ \\
\hline MV replacement & 238 & 31.9 \\
\hline Biological prosthesis & 154 & 64.7 \\
\hline Mechanical prosthesis & 84 & 35.3 \\
\hline MV repair & 507 & 68.1 \\
\hline Ring size, mean $\pm S D$ & 32 & \pm 3 \\
\hline Repairable valves* & 578 & \\
\hline Attempted repair & 524 & 90.7 \\
\hline Intentionally replaced & 54 & 9.3 \\
\hline Successful repair of attempted repair & 502 & 95.8 \\
\hline Successful repair of repairable valves & 502 & 86.9 \\
\hline Technique used & $\mathrm{n}$ & $\%$ of 507 \\
\hline $\begin{array}{l}\text { Ring+neochordae PMVL } \\
\quad \text { +Alfieri stitch }\end{array}$ & $\begin{array}{l}247 \\
+40\end{array}$ & $\begin{array}{l}48.7 \\
+7.9\end{array}$ \\
\hline $\begin{array}{l}\text { Ring annuloplasty } \\
\quad+\text { Alfieri stitch }\end{array}$ & $\begin{array}{l}127 \\
+31\end{array}$ & $\begin{array}{l}25.0 \\
+6.1\end{array}$ \\
\hline $\begin{array}{l}\text { Ring+neochordae AMVL } \\
\quad \text { +Alfieri stitch }\end{array}$ & $\begin{array}{l}25 \\
+4\end{array}$ & $\begin{array}{l}4.9 \\
+0.8\end{array}$ \\
\hline Ring+resection PMVL & 19 & 3.7 \\
\hline $\begin{array}{l}\text { Ring+neochordae both leaflets } \\
\quad+\text { Alfieri stitch }\end{array}$ & $\begin{array}{l}5 \\
+2\end{array}$ & $\begin{array}{l}1.0 \\
+0.4\end{array}$ \\
\hline Ring+neochordae PMVL+resection PMVL & 4 & 0.8 \\
\hline Ring+resection AMVL & 2 & 0.4 \\
\hline Ring+neochordae AMVL+resection PMVL & 1 & 0.2 \\
\hline Tricuspid valve repair & 56 & 7.5 \\
\hline Atrial fibrillation ablation & 132 & 17.7 \\
\hline Atrial septum defect repair & 30 & 4.0 \\
\hline Mean aortic closs-clamp time, min & $82 \pm 14$ & \\
\hline Mean cardiopulmonary bypass time, min & $122 \pm 35$ & \\
\hline
\end{tabular}

*See figure 1 for more details.

AMVL, anterior mitral valve leaflet; MV, mitral valve; PMVL, posterior mitral valve leaflet.

left ventricular free wall rupture, one patient had a severe stroke, one patient had arrhythmia (sudden death due to asystole on ICU), one patient had obstructive shock due to tamponade (despite rescue surgery) and one patient had hypovolemic shock due to excessive bleeding. The overall 30-day non-cardiac-related death was $0.3 \%$ $(2 / 745)$ both due to pneumosepsis.

\section{Primary outcome: 30-day major complications}

All complications that occurred within 30 days are shown in table 4.

Completeness of data was $98.0 \%$. Thirty-day major complication rate was $12.8 \%$ and the most common major complication was early re-exploration (within 7 days) for excessive bleeding $6.6 \%$ and $0.7 \%$ for late bleeding. The 30 -day stroke rate was $0.3 \%$. Less frequent major complications were LCOS necessitating mechanical support (ECMO, $n=4)$, of which two have successfully been weaned while the other two died. In one of the surviving patients, the operation was complicated by a free wall rupture with unknown cause that fortunately could be repaired, and one patient was preoperatively in cardiogenic shock due to papillary muscle rupture. The two patients who did not survive suffered respectively from obstructive shock due to tamponade (same patient as mentioned earlier) and cardiogenic shock due to cardiac amyloidosis (same patient as mentioned earlier). All baseline characteristics are used for univariate analysis and are shown in the addendum (online supplemental file 1). Multivariate analysis revealed left ventricular ejection fraction (LVEF) $<50 \%$ (OR $1.78 ; 95 \%$ CI 1.02 to 3.02) and estimated glomerular filtration rate (eGFR) $<60 \mathrm{~mL} /$ $\mathrm{min} / 1.73 \mathrm{~m}^{2}$ (OR $1.98 ; 95 \%$ CI 1.17 to 3.02 ) as independent predictors for major complications. Figure 2 shows a forest plot of the multivariate model. Age and mitral valve replacement were not significant in multivariate analysis and was left out of the model.

\section{Secondary outcome: 30-day any complications}

Any 30-day complication rate is shown in table 4. Some complications like delirium and infections were more often frequently present in the replacement group due to higher age (repair 60 years vs replacement 70 years, $\mathrm{p}<0.001)$. Univariate predictors are shown in the addendum (online supplemental file 1$)$. Higher age $(>70$ years) (OR 2.24; 95\% CI 1.55 to 3.26), female sex (OR 1.39; $95 \%$ CI 1.01 to 1.90 ), eGFR $<60 \mathrm{~mL} / \mathrm{min} / 1.73 \mathrm{~m}^{2}$ (OR 1.94; 95\% CI 1.21 to 3.17 ) and mitral valve replacement (OR 1.51; 95\% CI 1.05 to 2.17) were independent predictors for any complications (figure 3). Pulmonary hypertension was not significant in multivariate analysis and left out of the model. Independent predictors for minor complications were the same as found for any complications.

\section{DISCUSSION}

The current safety study provides a unique comprehensive overview of all 30-day complications based on MVARC definitions in a high-volume MIMVS centre showing a low mortality $(1.2 \%)$ and stroke rate $(0.3 \%)$. The major complication rate was $12.8 \%$ and left ventricular systolic function and renal function were both independent predictors.

As mentioned before, comparison of composite outcomes (eg, MACCE) is difficult due to inconsistency in definitions and is reported at $6.5 \%-33.0 \%$ for both MIMVS and sternotomy. ${ }^{37-21}$ Despite the result of our study $(12.8 \%)$ is within the range of literature, it is difficult to compare these outcomes due to multiple definitions. To the best of our knowledge, this is the first study reporting MIMVS outcomes based on MVARC definitions and we encourage others to report their postoperative outcomes as stated in the MVARC criteria. The MVARC is a collaboration between leading academic research organisations and physician-scientist specialising in mitral 


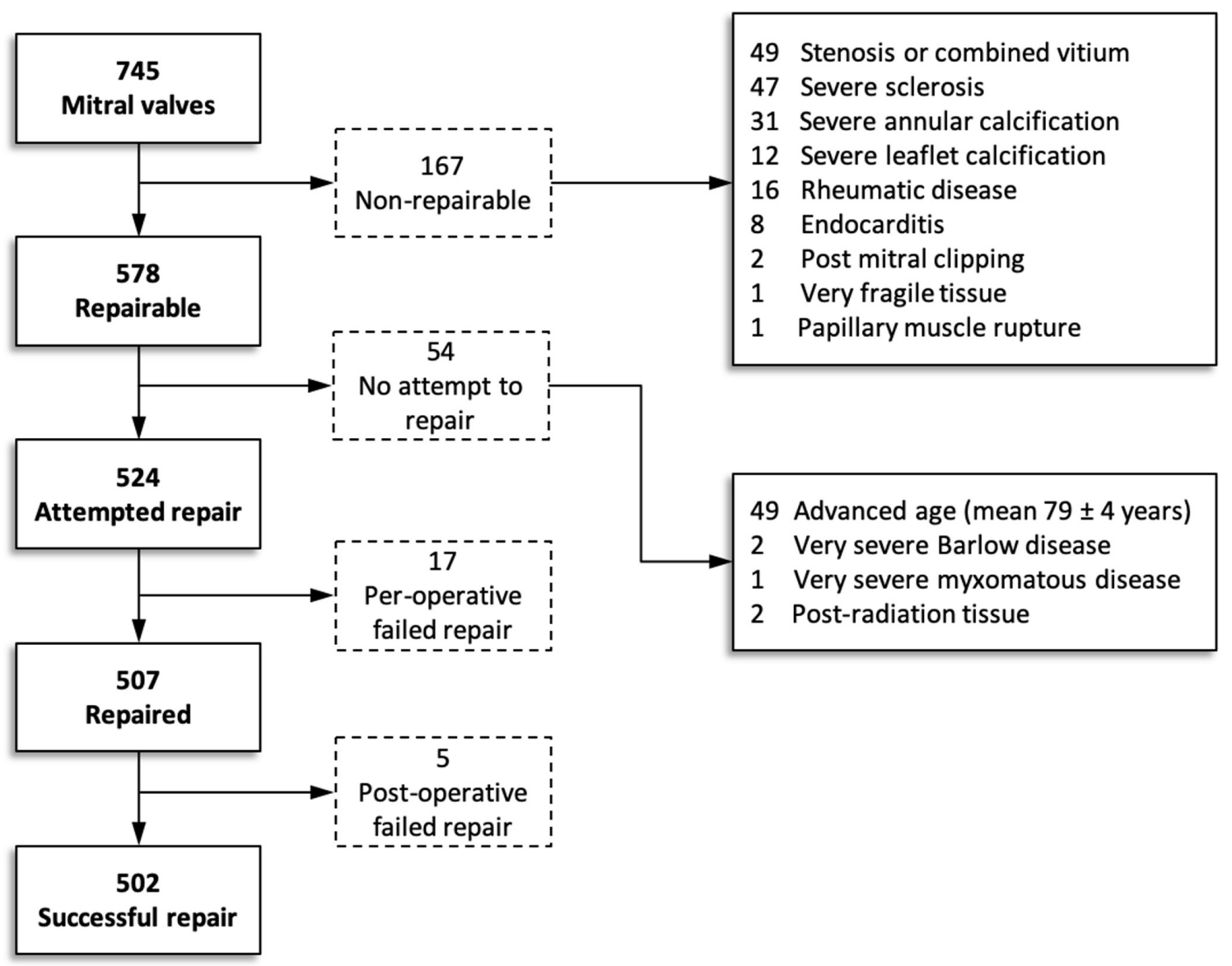

Figure 1 Flowchart of mitral valve repairability.

valve disease from the USA and Europe. The adoption of these recommendations will afford robustness and consistency in the comparative effectiveness evaluation of new devices, new approaches to treat mitral regurgitation and monitoring local and regional outcomes to guide quality improvement initiatives. ${ }^{13}$

MIMVS may be an alternative to conventional sternotomy approach with similar short-term and long-term mortality and in-hospital morbidity. ${ }^{11}$ Although there were some initial concerns about aortic injuries and particularly stroke in MIMVS, ${ }^{11}$ Sündermann $e t a l^{22}$ and more recently Al Otaibi et $a l^{23}$ showed similar stroke rates and mortality in two meta-analyses. As shown in our study, 30-day mortality (1.2\%) is comparable with other high-volume MIMVS centres $(0.8 \%-4.2 \%)$ and stroke rate $(0.3 \%)$ is in the lower spectrum $(2.0 \%-2.9 \%) .{ }^{1-4}$ Reported causes for higher stroke risk in MIMVS were retrograde arterial flow, use of endo-aortic balloon or reoperative cases. ${ }^{24}$ Although retrograde arterial flow was applied in the current cohort, our stroke rate was lower compared with other literature. After a brief tryout in 2014-2015, we chose not to use the endo-aortic balloon routinely in our centre since the transthoracic clamp is in our experience the most simple, easy-to-handle and safe technique for aortic occlusion, which might explain the low stroke rate of $0.3 \%$. However, a recent meta-analysis showed similar stroke and aortic dissection rates using the endo-aortic balloon, if performed under correct circumstances. ${ }^{25}$ MIMVS requires significant dedication to overcome the steep learning curve which can be discouraging for adapting MIMVS in institutional routine surgical programme. Holzhey et al reported approximately $75-125$ procedures to overcome the learning curve and $\sim 50$ procedures per year to maintain optimal results. ${ }^{26}$ The key to a safe technique to overcome these learning curve-related risks are, in addition to sufficient volume, a standardised technique and approach, a dedicated surgeon and a well-instructed operation team.

Although Cheng et al reported no higher re-exploration for bleeding in a large meta-analysis (MIMVS 3.5\% vs sternotomy $2.9 \%$; OR $0.91,95 \%$ CI 0.59 to 1.41$),{ }^{27}$ early re-thoracotomy for excessive blood loss was the most frequent major complication $(6.6 \%)$ and postoperative blood transfusion $(30.9 \%)$ was the most frequent minor complication. The latter was most frequently observed in patients with re-thoracotomy for excessive blood loss. In the majority $(57.1 \%)$, no active bleeding was found during re-exploration. In case of an active bleeding, the thoracic wall was the most common bleeding site. Our re-exploration rate is comparable with literature, which is reported at $4.9 \%-7.0 \% .{ }^{1-4}$ In our very early experience, the re-exploration rate was $10 \%$; therefore, we decided to inspect the thoracic wall with the videoscope before 


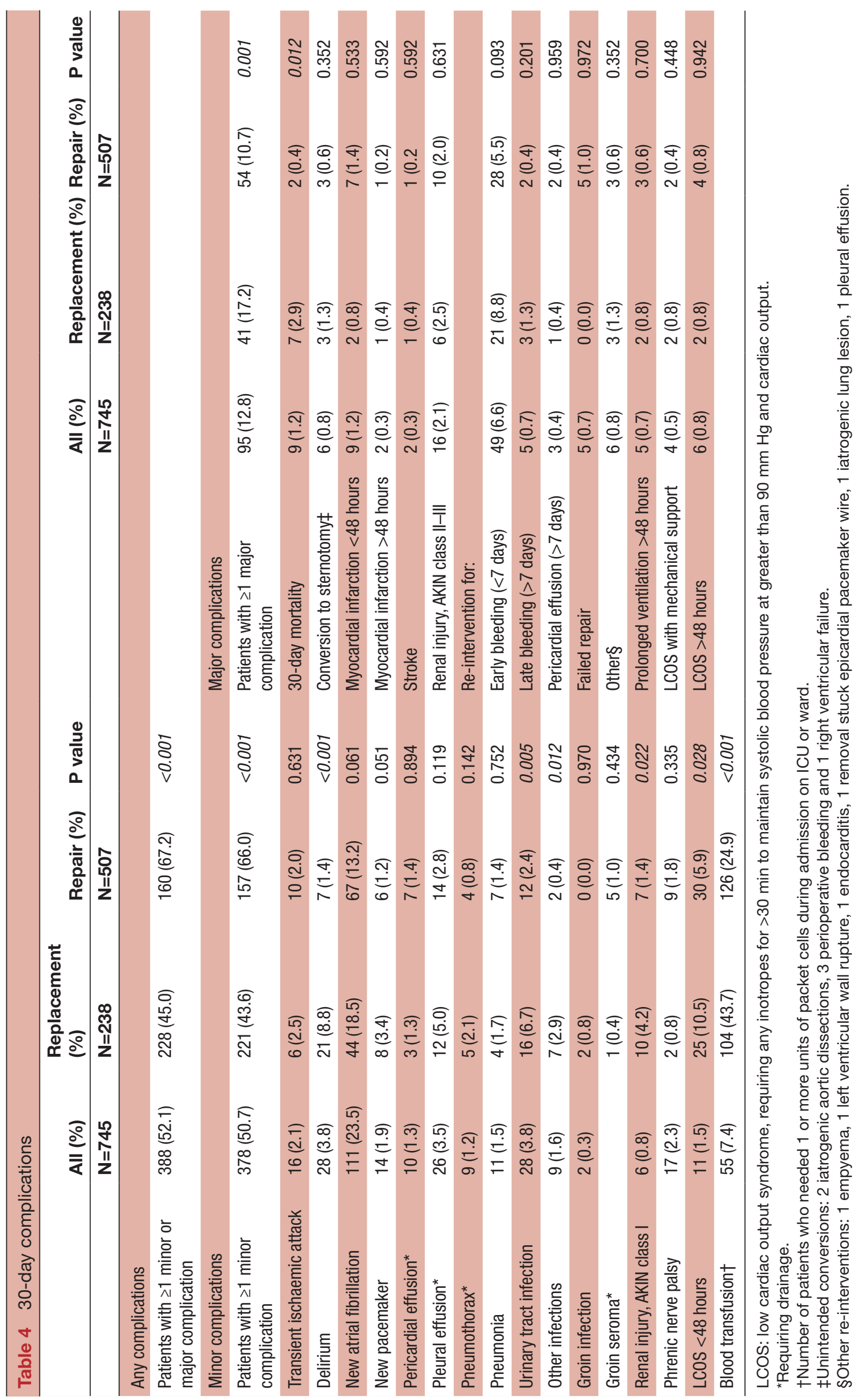




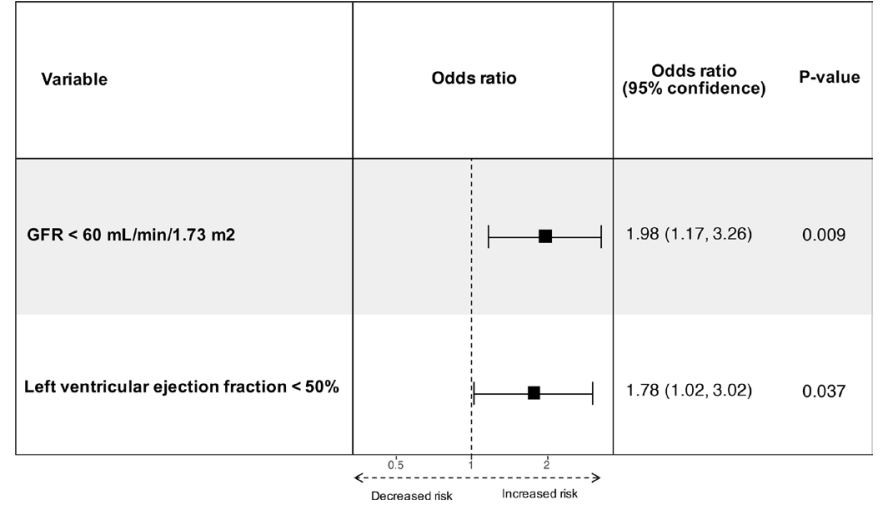

Figure 2 Forest plot of independent predictors for 30-day major complications. GFR, glomerular filtration rate.

closing the chest wall, leading to a decrease to $5 \%$ re-exploration rate in the last 3 years.

Surprisingly, an increased body mass index was not a predictor for any 30-day complications in this study, as we expected that they were at higher risk since the procedure is technically more challenging in these patients. We found excess 30-day major complications in patients with LVEF $<50 \%$ and decreased eGFR, which is in line with literature. $^{28-30}$

\section{Limitations}

There are few limitations in this study that needed to be addressed. First, all the data were collected retrospectively with all its known limitations. Furthermore, the data might have been biased by several time-dependent variables like operator experience. Three types of annuloplasty rings that were used in this time interval and different mitral valve repair techniques that were applied throughout the years. Ablation for atrial fibrillation was done in $17.7 \%$, while baseline characteristics show $36.5 \%$ atrial fibrillation. Possible explanation is a strict definition used for preoperative atrial fibrillation since all patients with any reported atrial fibrillation is scored, while possibly not all of them are good candidates for ablation. Due to the retrospective character of this study,

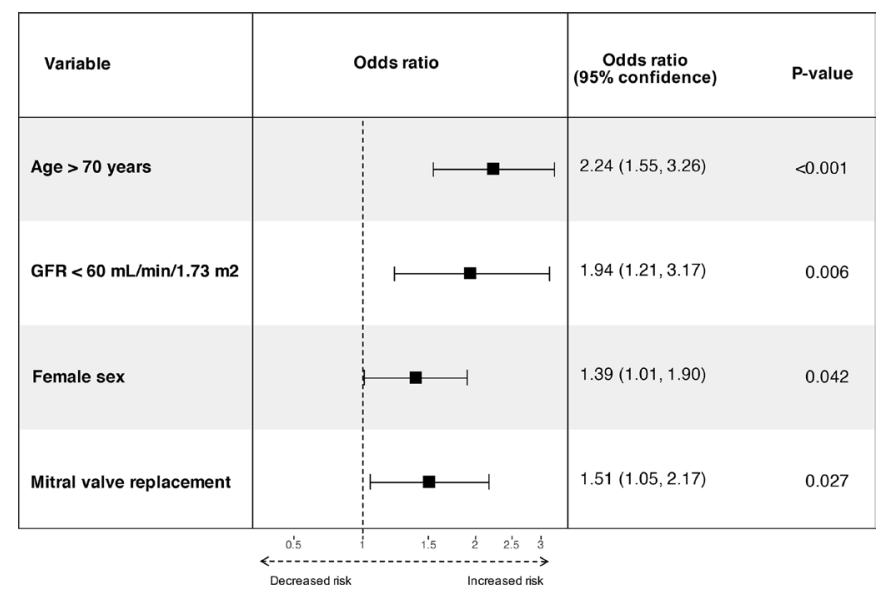

Figure 3 Forest plot of independent predictors for any 30day complications. GFR, glomerular filtration rate. it is not possible to reconstruct the decision-making process to analyse whether it was long persisting, symptomatic and what the left atrial volume index was. However, the same effect was observed in other large series with preoperative atrial fibrillation in $33 \%-37 \%$ and an ablation rate of $9.8 \%-17.2 \% .^{29}$

\section{CONCLUSIONS}

The current study shows that MIMVS is a safe technique and is associated with low 30-day mortality and stroke rate.

Contributors All listed authors contributed substantial to the work, approved the final version and agreed to be accountable for all aspects of the work in ensuring that questions related to the accuracy or integrity of any part of the work are appropriately investigated and resolved. KK and TLdK contributed equally to this work. BPvP and NS contributed equally to this work. KK: drafting of the work and writing of manuscript. Acquisition, analysis and interpretation of data. TLdK: conceptualisation and critical revision of the work. KFS: acquisition of data and critical revision of the work. JCK: analysis of data and critical revision of the work. NS: conceptualisation and critical revision of the work. BPvP: conceptualisation and critical revision of the work.

Funding The authors have not declared a specific grant for this research from any funding agency in the public, commercial or not-for-profit sectors.

Competing interests None declared.

Patient consent for publication Not required.

Ethical approval information Ethical approval for this study was waived by the ethical committee of St. Antonius Hospital (reference number W18.161) due to retrospective design of this study.

Provenance and peer review Not commissioned; externally peer reviewed.

Data availability statement Data are available on reasonable request.

Open access This is an open access article distributed in accordance with the Creative Commons Attribution Non Commercial (CC BY-NC 4.0) license, which permits others to distribute, remix, adapt, build upon this work non-commercially, and license their derivative works on different terms, provided the original work is properly cited, appropriate credit is given, any changes made indicated, and the use is non-commercial. See: http://creativecommons.org/licenses/by-nc/4.0/.

ORCID iD

Kinsing Ko http://orcid.org/0000-0001-5277-9448

\section{REFERENCES}

1 Davierwala PM, Seeburger J, Pfannmueller B, et al. Minimally invasive mitral valve surgery: "The Leipzig experience". Ann Cardiothorac Surg 2013;2:744-50.

2 Glauber M, Miceli A, Canarutto D, et al. Early and long-term outcomes of minimally invasive mitral valve surgery through right minithoracotomy: a 10-year experience in 1604 patients. $J$ Cardiothorac Surg 2015;10:181.

3 Grossi EA, Galloway AC, LaPietra A, et al. Minimally invasive mitral valve surgery: a 6-year experience with 714 patients. Ann Thorac Surg 2002;74:660-4.

4 Modi P, Rodriguez E, Hargrove WC, et al. Minimally invasive videoassisted mitral valve surgery: a 12-year, 2-center experience in 1178 patients. J Thorac Cardiovasc Surg 2009;137:1481-7.

5 Dogan S, Aybek T, Risteski PS, et al. Minimally invasive port access versus conventional mitral valve surgery: prospective randomized study. Ann Thorac Surg 2005;79:492-8.

6 El-Fiky MM, El-Sayegh T, El-Beishry AS, et al. Limited right anterolateral thoracotomy for mitral valve surgery. Eur J Cardiothorac Surg 2000;17:710-3.

7 Grant SW, Hickey GL, Modi P, et al. Propensity-matched analysis of minimally invasive approach versus sternotomy for mitral valve surgery. Heart 2019;105:1-7.

8 Akowuah E. UK Mini Mitral Trial [Internet]. CTSNet, Inc; 2019 [cited 9 Dec 2019]. Available: https://ctsnet.figshare.com/articles/UK_Mini_ Mitral_Trial/7548992/1 
9 Kastengren M, Svenarud P, Ahlsson A, et al. Minimally invasive mitra valve surgery is associated with a low rate of complications. J Intern Med 2019;286:614-26.

10 Jiang Q, Yu T, Huang K, et al. Feasibility, safety, and short-term outcome of totally thoracoscopic mitral valve procedure. $J$ Cardiothorac Surg 2018;13:133.

11 Falk V, Cheng DCH, Martin J, et al. Minimally invasive versus open mitral valve surgery: a consensus statement of the international society of Minimally Invasive Coronary Surgery (ISMICS) 2010. Innovations 2011;6:66-76.

12 Goldfarb M, Drudi L, Almohammadi M, et al. Outcome reporting in cardiac surgery trials: systematic review and critical appraisal. J Am Heart Assoc 2015;4:1-9.

13 Stone GW, Adams DH, Abraham WT, et al. Clinical trial design principles and endpoint definitions for transcatheter mitral valve repair and replacement: part 2: endpoint definitions: a consensus document from the mitral valve academic research consortium. J Am Coll Cardiol 2015;66:308-21.

14 Belluschi I, Lapenna E, Blasio A, et al. Excellent long-term results with minimally invasive edge-to-edge repair in myxomatous degenerative mitral valve regurgitation. Interact Cardiovasc Thorac Surg 2020;31:1-7.

15 Maganti M, Badiwala M, Sheikh A, et al. Predictors of low cardiac output syndrome after isolated mitral valve surgery. J Thorac Cardiovasc Surg 2010;140:790-6.

16 Seese LM, Sultan I, Gleason TG, et al. Outcomes of mitra valve repair versus replacement in the elderly. Ann Thorac Surg 2020;109:1202-9.

17 Gillinov AM, Gelijns AC, Parides MK, et al. Surgical ablation of atrial fibrillation during mitral-valve surgery. $N$ Engl J Med 2015;372:1399-409.

18 Heuts S, Olsthoorn JR, Hermans SMM, et al. Multidisciplinary decision-making in mitral valve disease: the mitral valve heart team. Neth Heart J 2019;27:176-84.

19 Perier P, Hohenberger W, Lakew F, et al. Rate of repair in minimally invasive mitral valve surgery. Ann Cardiothorac Surg 2013;2:751-7.

20 Shi WY, Hayward PA, Yap CH, et al. Training in mitral valve surgery need not affect early outcomes and midterm survival: a multicentre analysis. Eur J Cardio-thoracic Surg 2011;40:826-33.
21 Weiner MM, Hofer I, Lin H-M, et al. Relationship among surgical volume, repair quality, and perioperative outcomes for repair of mitra insufficiency in a mitral valve reference center. $J$ Thorac Cardiovasc Surg 2014;148:2021-6.

22 Sündermann SH, Sromicki J, Rodriguez Cetina Biefer H, et al. Mitral valve surgery: right lateral minithoracotomy or sternotomy? A systematic review and meta-analysis. J Thorac Cardiovasc Surg 2014;148:1989-95.

23 Al Otaibi A, Gupta S, Belley-Cote EP, et al. Mini-thoracotomy vs. conventional sternotomy mitral valve surgery: a systematic review and meta-analysis. J Cardiovasc Surg 2017;58:489-96.

24 Murzi M, Cerillo AG, Gasbarri T, et al. Antegrade and retrograde perfusion in minimally invasive mitral valve surgery with transthoracic aortic clamping: a single-institution experience with 1632 patients over 12 years. Interact Cardiovasc Thorac Surg 2017;24:363-8.

25 Rival PM, Moore THM, McAleenan A, et al. Transthoracic clamp versus endoaortic balloon occlusion in minimally invasive mitral valve surgery: a systematic review and meta-analysis. Eur J Cardiothorac Surg 2019;56:1-11.

26 Holzhey DM, Seeburger J, Misfeld M, et al. Learning minimally invasive mitral valve surgery: a cumulative sum sequential probability analysis of 3895 operations from a single high-volume center. Circulation 2013;128:483-91.

27 Cheng DCH, Martin J, Lal A, et al. Minimally invasive versus conventional open mitral valve surgery: a meta-analysis and systematic review. Innovations 2011;6:84-103.

28 Filsoufi F, Rahmanian PB, Castillo JG, et al. Early and late outcomes of cardiac surgery in patients with moderate to severe preoperative renal dysfunction without dialysis. Interact Cardiovasc Thorac Surg 2008;7:90-5.

29 Enriquez-Sarano M, Tajik AJ, Schaff HV, et al. Echocardiographic prediction of survival after surgical correction of organic mitra regurgitation. Circulation 1994;90:830-7.

30 Tribouilloy C, Grigioni F, Avierinos JF, et al. Survival implication of left ventricular end-systolic diameter in mitral regurgitation due to flail leaflets a long-term follow-up multicenter study. J Am Coll Cardiol 2009;54:1961-8. 